\title{
Hepatitis $C$ virus core protein induces fibrogenic actions of hepatic stellate cells via toll-like receptor 2
}

\author{
Martin Coenen', Hans Dieter Nischalke', Benjamin Krämer, Bettina Langhans, Andreas Glässner, Daniela Schulte, \\ Christian Körner, Tilman Sauerbruch, Jacob Nattermann and Ulrich Spengler
}

Hepatic stellate cells (HSCs) represent the main fibrogenic cell type accumulating extracellular matrix in the liver. Recent data suggest that hepatitis $\mathrm{C}$ virus (HCV) core protein may directly activate HSCs. Therefore, we examined the influence of recombinant HCV core protein on human HSCs. Primary human HSCs and the human HSC line LX-2 were stimulated with recombinant HCV proteins core and envelope 2 protein. Expression of procollagen type I $\alpha-1, \alpha$-smooth muscle actin, cysteine- and glycine-rich protein 2, glial fibrillary acidic protein, tissue growth factor $\beta 1$, matrix metalloproteinases 2 (MMP2) and 13, tissue inhibitor of metalloproteinases 1 and 2 was investigated by real-time PCR. Intracellular signaling pathways of ERK1/2, p38 and, jun-amino-terminal kinase (JNK) were analyzed by western blot analysis. Recombinant HCV core protein induced upregulation of procollagen type I $\alpha-1, \alpha$-smooth muscle actin, MMP 2 and 13, tissue inhibitor of metalloproteinases 1 and 2, tissue growth factor $\beta 1$, cysteine- and glycine-rich protein 2 , and glial fibrillary acidic protein mRNA expression, whereas HCV envelope 2 protein did not exert any significant effect. Blocking of toll-like receptor 2 (TLR2) with a neutralizing antibody prevented mRNA upregulation by HCV core protein confirming that the TLR2 pathway was involved. Furthermore, western blot analysis revealed HCV-induced phosphorylation of the TLR2-dependent signaling molecules ERK1/2, p38 and JNK mitogen-activated kinases. Our in vitro results demonstrate a direct effect of HCV core protein on activation of HSCs toward a profibrogenic state, which is mediated via the TLR2 pathway. Manipulating the TLR2 pathway may thus provide a new approach for antifibrotic therapies in HCV infection. Laboratory Investigation (2011) 91, 1375-1382; doi:10.1038/labinvest.2011.78; published online 2 May 2011

KEYWORDS: core protein, hepatic stellate cells, hepatitis C virus, liver fibrosis, toll-like receptor 2

Chronic hepatitis $\mathrm{C}$ virus (HCV) infection is a major cause of chronic liver disease leading to hepatic fibrosis und ultimately to liver cirrhosis. ${ }^{1,2}$ Hepatic stellate cells (HSCs) are the major producers of extracellular matrix proteins and have a key role in the development of liver fibrosis. ${ }^{3-6}$ After hepatic injury, HSCs become activated and secrete markedly increased amounts of collagen type I and III, the principal matrix proteins in hepatic fibrosis ${ }^{7}$ and express the intermediate filament proteins $\alpha$-smooth muscle actin (SMA), endoded by the ACTA2 gene, and glial fibrillary acidic protein (GFAP). In addition, they express tissue growth factor $\beta 1$ (TGF- $\beta 1$, encoded by TGFB1), and CSRP2, a gene in the liver exclusively expressed by HSC coding the cysteine- and glycine-rich protein $2 .^{8-12}$ Furthermore, activated HSC produce factors involved in tissue remodelling: ${ }^{13}$ matrix metalloproteinases
2 (MMP2, gelatinase A, collagenase IV) and 13 (MMP13, matrix metallopeptidase 13 , collagenase 3 ) are proteolytic enzymes activated during hepatic fibrogenesis degrading extracellular matrix, thus contributing to the destruction of the physiological liver architecture and further activation of HSC. ${ }^{14}$ On the other hand, MMPs facilitate penetration of inflammatory cells into the liver further enhancing local tissue damage. This process is controlled by specific tissue inhibitors of metalloproteinase (TIMP) acting as antifibrolytic enzymes. ${ }^{15}$ In particular, TIMP1 and TIMP2 are activators of MMP9 and MMP2, respectively, by cleaving the precursor proteins. ${ }^{16}$

HCV is a single-stranded RNA virus composed of structural (core, envelope 1 and 2 (E1 and 2)) and non-structural proteins $2-5 .^{17}$ Apart from their role in viral replication, HCV proteins can affect a variety of cellular functions in 
infected cells. ${ }^{18,19}$ HCV core protein is an RNA-binding dimeric $\alpha$-helical protein that participates in the formation of the viral nucleocapsid. ${ }^{19}$ The protein exerts a number of biological actions in many cell types, including hepatocytes. ${ }^{20}$ These effects depend on the target cell type, and include control of cell growth, apoptosis, oxidative stress, carcinogenesis and immunomodulation. ${ }^{21-25} \mathrm{HCV}$ core protein can also trigger inflammatory cells and thus contribute to the immunopathology of HCV infection. ${ }^{26,27}$

Adenoviral infection of HSC with a HCV core protein expressing construct-induced cell proliferation and increased procollagen type I $\alpha-1$ gene (COL1A1) expression. ${ }^{28}$ We and others have recently shown that HCV core protein triggers inflammatory cell activation by stimulating the pattern recognition receptor toll-like receptor 2 (TLR2). ${ }^{29-31}$

After ligand binding, TLR2 recruits different signaling molecules that are also involved in the regulation of fibrosis. These include the adapter molecule MyD88, triggering interleukin-1 receptor-associated kinase activated by phosphorylation and leading to the recruitment of the mitogen activated kinase (MAPK) pathways jun-amino-terminal kinase (JNK), p38 and ERK1/2 that induce NFkB activation. ${ }^{32}$

Thus, we hypothesized that stimulation of TLR2 on HSC by HCV core protein increased fibrogenesis during HCV infection. In this study, we present evidence that HCV core protein stimulates the expression of the fibrogenic genes COL1A1, ACTA2, MMP2, MMP13, TIMP1, TIMP2, TGFB1, CSRP2 and GFAP via triggering of TLR2 and activation of TLR2-dependent signaling pathways.

\section{MATERIALS AND METHODS FACS Analysis}

The following antibodies were used for FACS analysis: PE-conjugated anti-TLR2 (eBioscience, San Diego, CA, USA), PE-conjugated anti-CD81 (BD Bioscience, Heidelberg, Germany). Cell viability was assessed by propidium iodide (BD Bioscience) staining. After incubation of the cells with $10 \mu$ antibody for 20 min and washing in PBS, samples were analyzed on a FACScalibur flow cytometer using CellQuest Pro software (BD Bioscience) and Flowjo 7.2.2 (Treestar, Ashland, OR, USA).

\section{Cell Culture}

Isolated human primary HSCs (pHSC, ScienCell, Carlsbad, CA, USA) were used between passage 2 and 6 , and cultured in defined medium supplemented with $2 \%$ fetal bovine serum and $50 \mathrm{U} / \mathrm{ml}$ penicillin and $50 \mu \mathrm{g} / \mathrm{ml}$ streptomycin (all ingredients obtained from ScienCell). The LX-2 human HSC line was kindly provided by Dr SL Friedman (Mount Sinai School of Medicine, New York, NY, USA). ${ }^{33}$ LX-2 cells were grown and maintained in Dulbecco's modified Eagle's Medium (PAA Laboratories, Pasching, Austria) supplemented with $2 \%$ fetal calf serum (Biochrom AG, Berlin, Germany) and $50 \mathrm{U} / \mathrm{ml}$ penicillin and $50 \mu \mathrm{g} / \mathrm{l}$ streptomycin (PAA Laboratories). Cells were cultured in $75 \mathrm{~cm}^{2}$ flasks (Greiner
Bio-One, Frickenhausen, Germany) until $90 \%$ confluence and then trypsinized $(0,05 \%$ trypsin, $0,02 \%$ EDTA, PAA Laboratories) and reseeded at a ratio of 1:3 or used for biological studies. Morphology was assessed with a Axiovert $200 \mathrm{M}$ microscope (Zeiss, Jena, Germany).

\section{Cell Stimulation}

pHSC and LX-2 cells were plated in 12-well plates at $80 \%$ confluence and grown in stellate cell medium or serumdepleted Dulbecco's modified Eagle's Medium with $0.2 \%$ bovine serum albumin (Sigma, St Louis, MO, USA) for $48 \mathrm{~h}$, respectively. Then either $1 \mu \mathrm{g} / \mathrm{ml}, 2 \mu \mathrm{g} / \mathrm{ml}$ or $3 \mu \mathrm{g} / \mathrm{ml}$ of recombinant full-length HCV core protein (kindly provided by M Houghton), $3 \mu \mathrm{g} / \mathrm{ml}$ of truncated $\mathrm{HCV}$ core protein (amino acids 1-115, Mikrogen, Neuried, Germany), $10 \mu \mathrm{g} / \mathrm{ml}$ of HCV E2 protein (kindly provided by M Houghton) or $5 \mathrm{ng} / \mathrm{ml}$ of lipopolysaccharide (LPS; Sigma-Aldrich, Taufkirchen, Germany) were added for another $20 \mathrm{~h}$. For western blot analysis, LX-2 cells were stimulated with HCV core protein for $15 \mathrm{~min}$ before cell harvesting. As a control HCV core protein was heat inactivated at $90^{\circ} \mathrm{C}$ for $30 \mathrm{~min}$. To block TLR2, the anti-TLR2 antibody TL2.1 or an isotype control antibody (eBioscience) was added at $2 \mathrm{~h}$ before stimulation with HCV core protein.

\section{Proliferation Assay}

Serum-depleted LX-2 cells in different cell densities were incubated over $48 \mathrm{~h}$ in 96-well microtitre plates (Nunc, Wiesbaden, Germany) in Dulbecco's modified Eagle's Medium containing $0.2 \%$ bovine serum albumin and stimulated with $3 \mu \mathrm{g} / \mathrm{ml} \mathrm{HCV}$ core protein. After $20 \mathrm{~h}$, stimulated HSC were labeled with $1 \mathrm{mCi}$ of $[3 \mathrm{H}]$ thymidine (Amersham, Braunschweig, Germany) at $4 \mathrm{~h}$ before the cells were harvested. All experiments were performed in triplicate. Stimulation indices were calculated as the ratio of $[3 \mathrm{H}]$ thymidine uptake in relation to the culture medium control. Stimulation indices $\geqslant 2$ were considered to indicate positive proliferative responses of the LX-2 cells.

\section{RNA Extraction and Reverse Transcription}

Total RNA was extracted using the RNeasy Mini kit (Qiagen, Hilden, Germany) according to the manufacture's standard protocol. The extracted RNA was eluted in $50 \mu \mathrm{l}$ of RNAsefree water and stored at $-80^{\circ} \mathrm{C}$. Reverse transcription was carried out for $15 \mathrm{~min}$ at $42^{\circ} \mathrm{C}$ with $1 \mu \mathrm{g}$ template RNA in a final volume of $20 \mu \mathrm{l}$ using the Quantitect RT kit (Qiagen) following the manufacturer's recommendations. cDNA samples were stored at $-20^{\circ} \mathrm{C}$.

\section{Real-Time Quantitative PCR}

For detection of COL1A1, ACTA2, MMP2 and MMP13, TIMP1 and TIMP2, TGFB1, CSRP2 and GFAP QuantiTect Primer Assays from Qiagen were used according to the manufacturer's recommendations. Primers of the housekeeping genes, $\beta$-actin, were purchased from TibMolbiol 
(Berlin, Germany): sense 5'-TGGCATCGTGATGGACTCC-3', antisense $5^{\prime}$-AATGTCACGCACGATTTCCC-3'. Quantification of cDNA transcripts was performed using a Light Cycler device (Roche Diagnostics, Mannheim, Germany). In brief, $2 \mu$ l LightCycler-FastStart DNA Master 'Plus' SYBR Green I (Roche Diagnostics), $1 \mu \mathrm{l}$ of each primer $0.5 \mu \mathrm{M}, 1 \mu \mathrm{l}$ of cDNA preparation and $6 \mu \mathrm{l}$ of water were mixed in a total volume of $10 \mu \mathrm{l}$ for each PCR reaction. PCR settings were: $95^{\circ} \mathrm{C}$ for $2 \mathrm{~min}, 50$ amplification cycles for COL1A1, MMP2 and 40 cycles for TIMP2, ACTA2, MMP13, TIMP1, TGFB1, CSRP2 and GFAP with denaturation of $1 \mathrm{~s}$ at $95^{\circ} \mathrm{C}, 5 \mathrm{~s}$ of $55^{\circ} \mathrm{C}$ for DNA strand annealing and extension at $55^{\circ} \mathrm{C}$ for $5 \mathrm{~s}$. $\beta$-Actin PCR was carried out for 45 cycles with denaturation at $95^{\circ} \mathrm{C}$ for $2 \mathrm{~s}$, annealing at $60^{\circ} \mathrm{C}$ for $5 \mathrm{~s}$, extension at $72^{\circ} \mathrm{C}$ for $10 \mathrm{~s}$ and fluorescence acquisition at $89^{\circ} \mathrm{C}$.

After each PCR run, a melting curve analysis was carried out. Fluorescence was measured after each elongation step at $87^{\circ} \mathrm{C}$ for COL1A1, $81^{\circ} \mathrm{C}$ for MMP2 and $72^{\circ} \mathrm{C}$ for TIMP2, ACTA2, MMP13, TIMP1, TGFB1, CSRP2 and GFAP. mRNA concentrations were determined semiquantitatively using purified PCR products in five $\log 10$ serial dilutions as external standards. Target gene mRNA levels were normalized with respect to mRNA levels of the housekeeping gene $\beta$-actin. The LightCycler software version 3.5 was used in all PCR experiments. RNA extraction, reverse transcription, PCR and post-PCR procedures were carried out in separated areas of the laboratory to prevent carry over contamination. Identity of PCR products was confirmed by melting curve analysis and $2 \%$ agarose gel electrophoresis.

\section{Western Blot Analysis}

Western blots were performed following standard protocols. In brief, cell lysates were dissolved in SDS sample buffer and $20 \mu \mathrm{g}$ of protein were applied to a $10 \%$ polyacrylamide slab gel. After separation by electrophoresis, proteins were transferred to a nitrocellulose membrane (Schleicher and Schuell, Dassel, Germany) by electroblotting. The membrane was placed in blocking buffer (5\% non-fat dry milk dissolved in $150 \mathrm{mM} \mathrm{NaCl}, 50 \mathrm{mM}$ Tris, $\mathrm{pH} 7.5$ and $0.1 \%$ Tween-20) for $1 \mathrm{~h}$. Next, the membrane was incubated for $1 \mathrm{~h}$ at room temperature using the following antibodies: anti-ERK1/2, anti-phospho-ERK1/2, anti-p38, anti-phospho-p38, antiJNK and anti-phospho-JNK (Cell Signaling, Danvers, MA, USA). Then the membrane was washed three times with $\mathrm{PBS} / 0.1 \%$ Tween-20, and incubated with horseradish peroxidase-labeled goat anti-rabbit IgG (Zymed, South San Francisco, CA, USA) at a dilution of $1: 5000$ in $\mathrm{PBS} / 0.1 \%$ Tween-20. After washing three more times in $\mathrm{PBS} / 0.1 \%$ Tween-20, the membrane was soaked in ECL detection reagent and exposed to Hyperfilm MP (Amersham) for $10 \mathrm{~s}$.

\section{Statistical Analysis}

Statistical analysis was performed with SPSS software version 17.0.0 (SPSS Inc., Chicago, IL, USA) and GraphPad Prism for Windows version 4.00. Data were compared by two-tailed
Mann-Whitney test as appropriate. Data are reported as means \pm s.d. Results with $P<0.05$ were regarded as statistically significant.

\section{RESULTS \\ HCV Core Protein Induces Expression of Fibrogenic Relevant Genes}

We first studied the effect of HCV core protein on the expression of fibrogenic genes. As shown in Figure 1, incubation with recombinant $\mathrm{HCV}$ core protein $(3 \mu \mathrm{g} / \mathrm{ml})$ resulted in significantly upregulated expression of COL1A1 in both pHSC (2.09-fold $(P=0.0237)$, Figure 1a) and LX-2 cells (1.86-fold $(P=0.002)$, Figure $1 b)$. Furthermore, HCV core protein induced an increase in mRNA expression of various other fibrogenic marker genes ACTA2 (1.58-fold in pHSC, $P=0.0079 ; 2.47$-fold in LX-2 cells, $P=0.0079), M M P 2$ (2.45-fold in pHSC, $P=0.0237 ; \quad 1.44$-fold in LX-2 cells, $P=0.0028$ ), MMP13 (1.51-fold in pHSC, $P=0.0079$; 1.73-fold in LX-2 cells, $P=0.0317)$, TIMP1 $(2.07$-fold in pHSC, $P=0.079 ; 2.29$-fold in LX-2, $P=0.0079$ ), TIMP2

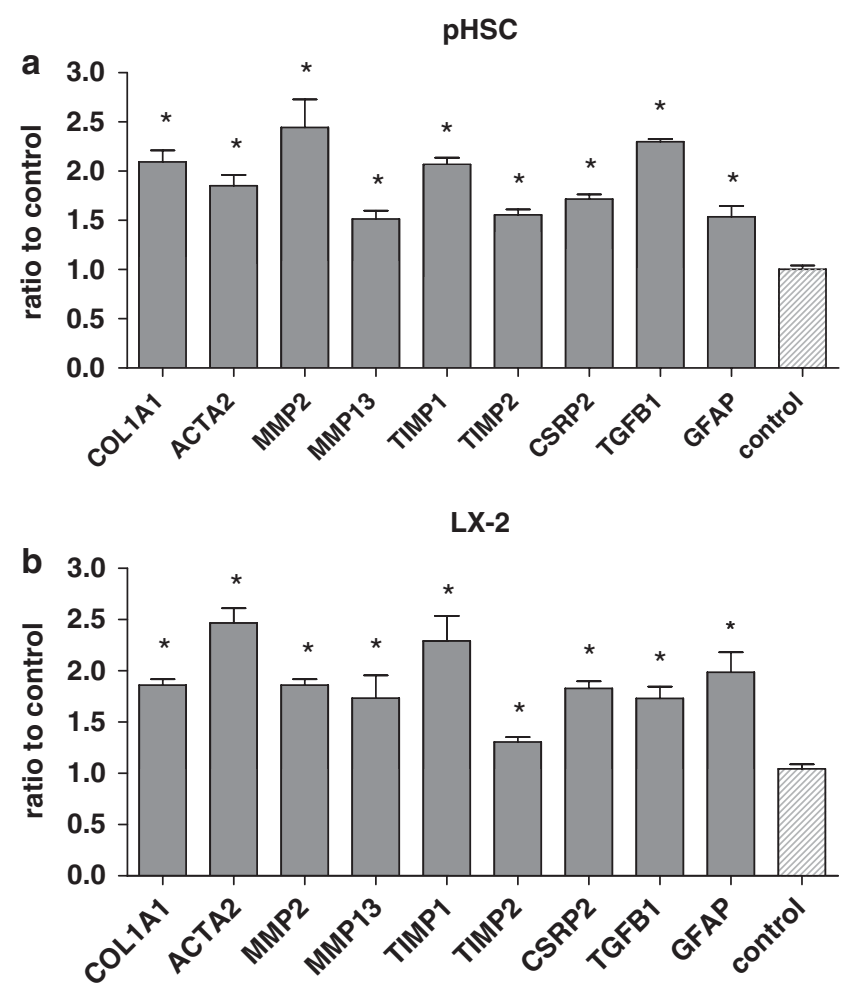

Figure 1 Upregulated expression of fibrogenic genes after stimulation with $\mathrm{HCV}$ core protein. This figure summarizes the analysis of mRNA levels using quantitative real-time reverse transcription PCR from six independent experiments. Stimulation of primary HSC (a) and serum-starved LX-2 cells (b) with $3 \mu \mathrm{g} / \mathrm{ml} \mathrm{HCV}$ core protein resulted in a significantly upregulated expression of COL1A1, ACTA2, MMP2, MMP13, TIMP1, TIMP2, TGFB1, CSRP2 and GFAP. Target mRNA expression was normalized with respect to mRNA levels of the housekeeping gene $\beta$-actin. Increase in gene expression is shown in comparison with untreated controls. ${ }^{\star} P<0.05$ compared with untreated controls. 
(1.44-fold in pHSC, $P=0.00237 ; 1.31$-fold in LX-2, $P=0.0028)$, TGFB1 (2.30-fold in pHSC, $P=0.0117$; 1.73 fold in LX-2, $P=0.0079)$, CSRP2 (1.69-fold in pHSC, $P=0.0073$; 1.83 -fold in LX-2, $P=0.0049)$ and GFAP (1.48fold in pHSC, $P=0.073 ; 1.99$-fold in LX-2, $P=0.0079$ ) compared with unstimulated cells (Figure 1). HCV-induction of genes in HSCs was confirmed by the use of a truncated HCV core protein (amino acids 1-115) (Figure 2) and showed a nearly linear dose-dependent kinetics (Figure 3). HCV envelope glycoprotein E2, which interacts with HSC

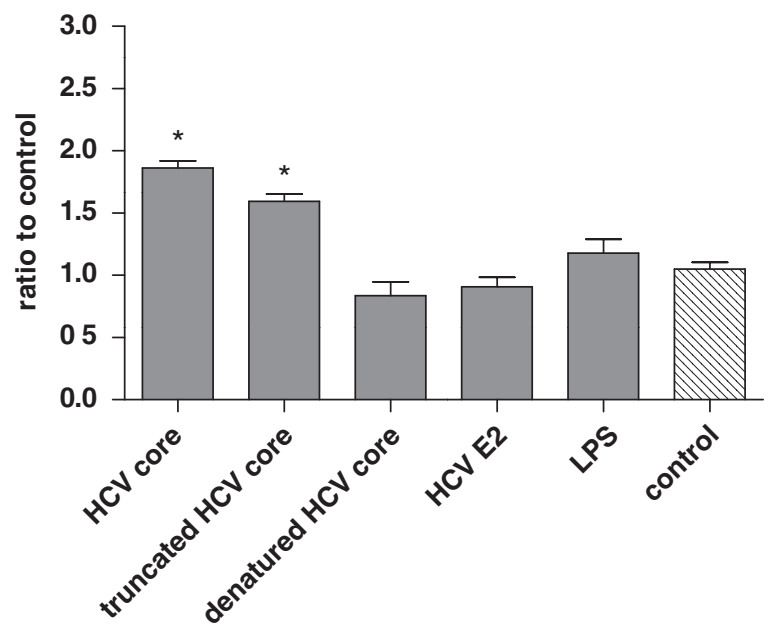

Figure 2 Full-length and truncated (aa1-115) recombinant HCV core protein but not heat-denatured HCV core protein, HCV E2 protein and the TLR4 ligand LPS upregulate mRNA expression of fibrogenic genes. The figure shows the COL1A1 mRNA expression levels in LX2 cells from three independent experiments. In contrast to $3 \mu \mathrm{g} / \mathrm{ml}$ full-length (HCV core) and truncated HCV core (truncated HCV core) protein, stimulation of serum-starved LX-2 cells with $3 \mu \mathrm{g} / \mathrm{ml}$ heat-denatured HCV core protein, $10 \mu \mathrm{g} / \mathrm{ml} \mathrm{HCV} \mathrm{E2} \mathrm{protein} \mathrm{and} \mathrm{the} \mathrm{TLR4} \mathrm{ligand} \mathrm{LPS}(5 \mathrm{ng} / \mathrm{ml})$ did not result in upregulated expression of COL1A1 mRNA. Gene expression levels in stimulated cells are shown as ratios with reference to untreated control cells. ${ }^{\star} P<0.05$ compared to control cells.

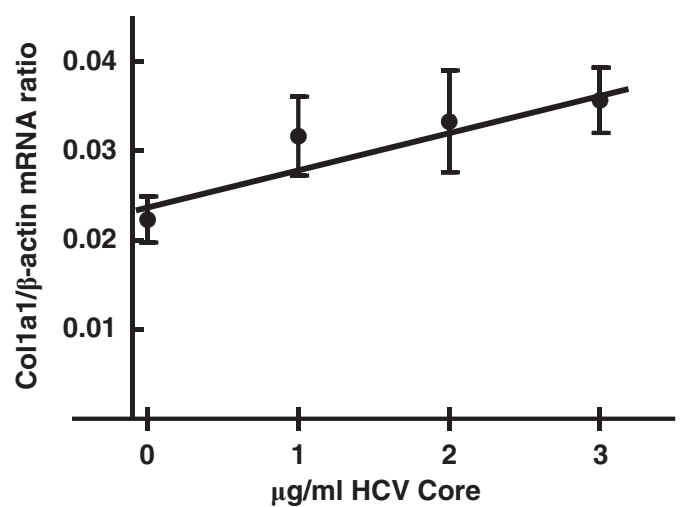

Figure 3 Induction of COL1A1 by HCV core protein shows a nearly linear dose-dependent kinetics. Serum-depleted LX-2 cells were stimulated with $0 \mu \mathrm{g} / \mathrm{ml}, 1 \mu \mathrm{g} / \mathrm{ml}, 2 \mu \mathrm{g} / \mathrm{ml}$ and $3 \mu \mathrm{g} / \mathrm{ml} \mathrm{HCV}$ core protein. COL1A1 mRNA levels were normalized with respect to mRNA levels of the housekeeping gene $\beta$-actin. The figure shows average values produced by three independent experiments. via CD81 but not TLR2, did not stimulate the LX-2 cells (Figure 2).

\section{Proliferation of HSCs is not Affected by Stimulation with HCV Core Protein}

We then examined the effect of HCV core protein on cell viability and proliferation. LX-2 cells were plated in different cell densities and then incubated for $48 \mathrm{~h}$ in serum-depleted medium $(0.2 \%$ bovine serum albumin) before stimulation with HCV core protein for $24 \mathrm{~h}$. On microscopic examination, morphology did not change (Figure 4). Furthermore, there was no increase in propidium iodide labeling in the FACS analysis, suggesting that cell viability of the cells was also not affected by the recombinant HCV core protein (data not shown). In addition, cell proliferation in different cell densities analyzed by 3H-thymidine incorporation did not show any relevant changes to basal proliferation (data not shown). We did not find any evidence that contact inhibition was the cause for unchanged proliferation rates.

\section{HSCs Express TLR2}

Next, we analyzed the expression of TLR2 on HSCs by flow cytometry. As described for other primary human and murine HSCs ${ }^{28,29}$ incubation with an antibody against TLR2 resulted in considerable fluorescent staining of pHSC and LX-2 cells as compared with incubation with an isotypematched control antibody (Figure 5a). TLR2 expression levels were stable and not altered by the duration of culture or by culture in serum-containing or -depleted media.

\section{Induction of Fibrogenic Genes is Inhibited by Blockade of the TLR2 Receptor}

As HCV core protein has been shown to interact with TLR2, we hypothesized an activation of fibrogenic genes by HCV core protein via TLR2. Therefore, LX-2 cells were stimulated with HCV core protein after preincubation with an TLR2blocking antibody. Blocking of TLR2 prevented induction of the COL1A1 by HCV core protein $(P=0.0264$; Figure 6$)$, whereas a control antibody had no effect. Denaturing HCV core protein by heat inactivation abolished its stimulating effect on LX-2 cells, suggesting a conformation-dependent interaction (Figure 2). LPS, a TLR4 ligand, ${ }^{30}$ did not induce COL1A1 upregulation, thus excluding inadvertent activation of LX-2 cells by endotoxin contamination (Figure 2).

\section{HCV Core Protein Stimulation Leads to Increased Phosphorylation of TLR2-Dependent Signaling Proteins}

Next, we examined the signaling mechanisms downstream of TLR2 activation. Therefore, cell extracts were prepared for western blot analysis after incubation of LX-2 cells with HCV core protein. Immunoblotting with an antibody directed against the phosphorylated form of the ERK1/2 MAPK revealed that phosphorylation of these proteins was increased in $\mathrm{HCV}$ core protein-stimulated LX-2 cells $(P<0.05$, Figure $7 \mathrm{a})$. On the contrary, blotting with an antibody 
a

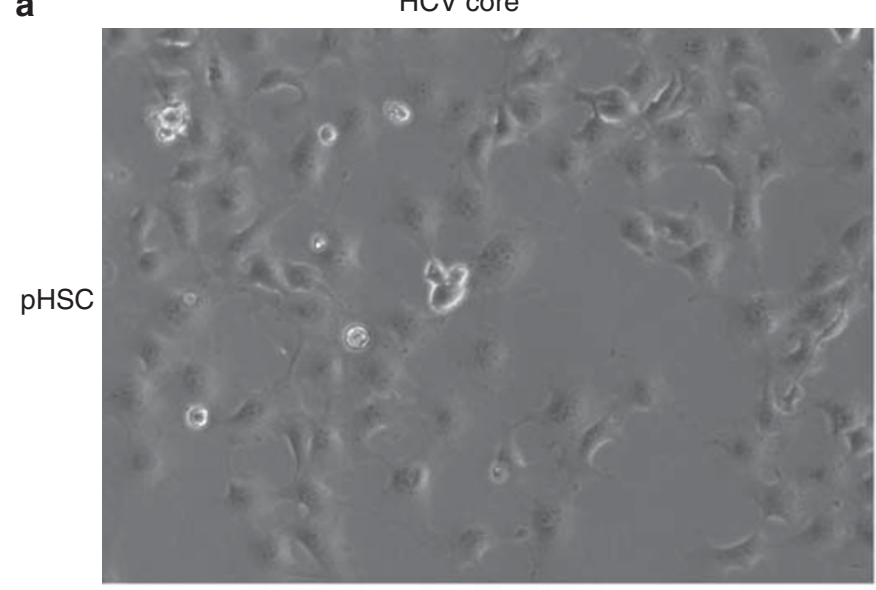

b

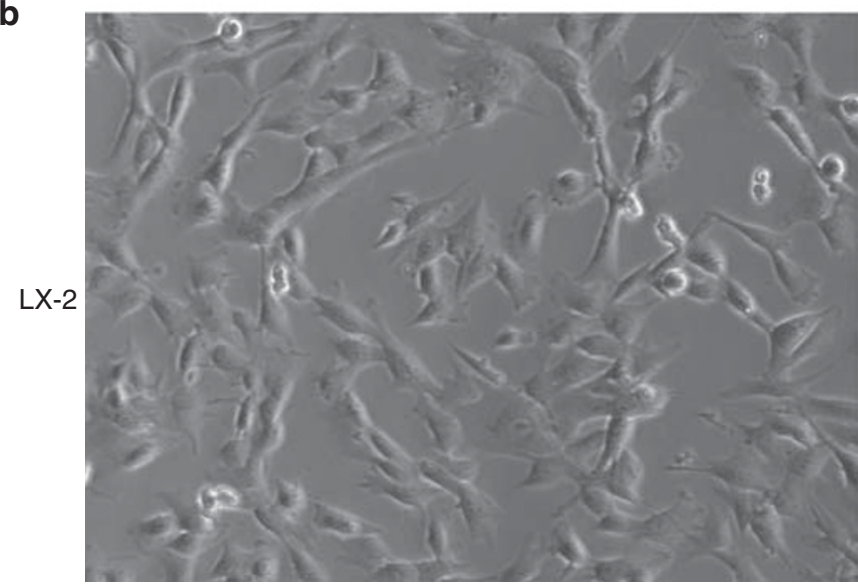

control
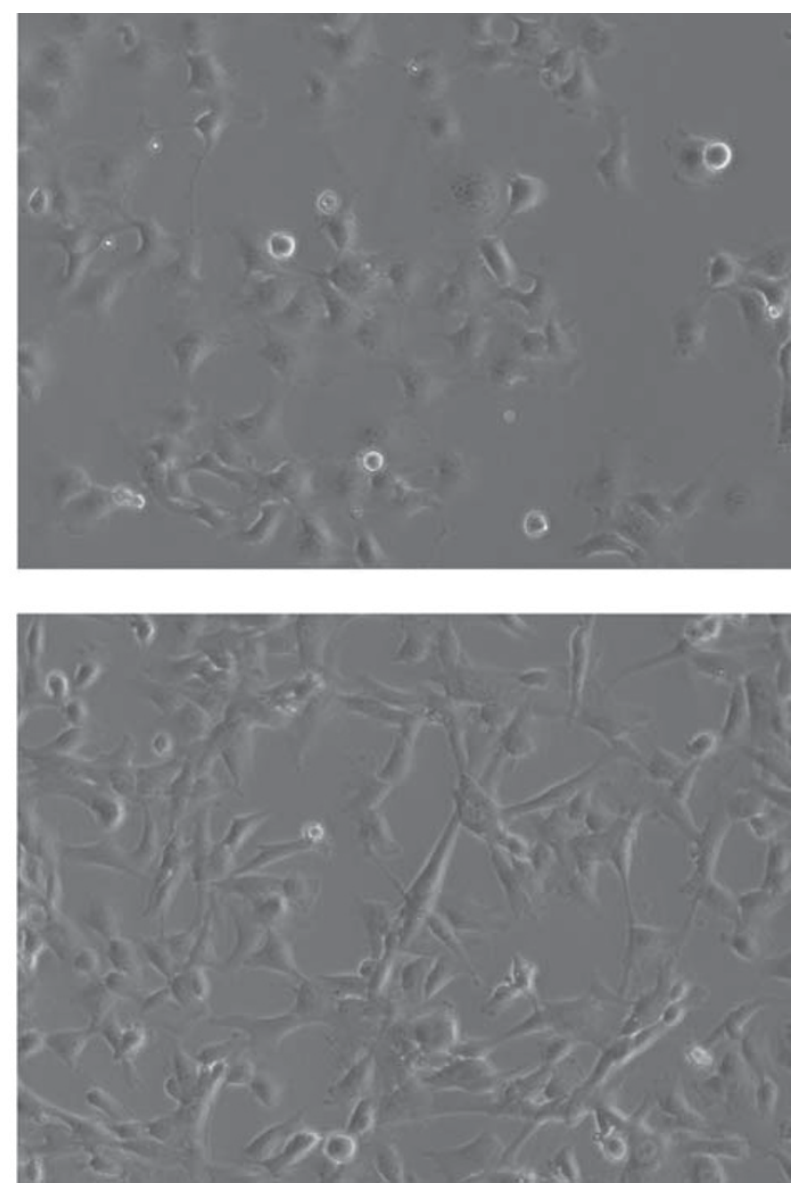

Figure 4 Morphology of pHSC and LX2 cells is not changed by stimulation with HCV core protein. The figure shows representative microscopic examinations of pHSC (a) and LX-2 cells (b) after stimulation with $3 \mu \mathrm{g} / \mathrm{ml} \mathrm{HCV}$ core protein (left) compared with untreated controls (right) demonstrating no relevant morphological changes.

detecting both phosphorylated and unphosphorylated ERK1/ 2 indicated that the amount of total ERK protein had not changed (data not shown). Thus, the HCV core protein induced increase of ERK1/2 phosphorylation was not the result of an altered abundance of ERK1/2 protein. Similarly, HCV core protein stimulation resulted in increased phosphorylation of $\mathrm{p} 38$ and JNK MAPKs $(P<0.05$, Figure $7 \mathrm{~b}$ and c). Inhibition of TLR2 activation with a blocking antibody specifically prevented phosphorylation of the MAPK signaling molecules confirming involvement of the TLR2dependent pathways.

\section{DISCUSSION}

HSCs have a key role in the development of fibrosis in chronic liver disease because they synthesize and secrete extracellular matrix proteins, chemokines and other factors contributing to an inflammatory environment and fibrotic tissue remodeling in the liver. ${ }^{34}$ Although chronic HCV infection is a major cause of liver fibrosis little is known about HCV-specific steps in the pathogenesis of liver fibrosis. ${ }^{35}$ As it has been shown that HCV proteins can directly activate $\mathrm{HSCs},{ }^{28}$ the aim of this study was to further characterize the activation of human HSC by HCV core protein. Here we demonstrate that the interaction of $\mathrm{HCV}$ core protein with TLR2 on human HSCs results in the downstream induction of TLR2-dependent intracellular signaling pathways and leads to increased expression of the profibrogenic genes COL1A1, ACTA2, MMP2, MMP13, TIMP1, TIMP2, TGF- $\beta 1, C S R P 2$ and GFAP. To our knowledge, this is the first report showing a direct interaction of HCV core protein with HSCs via TLR2.

Increased expression of fibrogenic genes in pHSC and LX-2 cells induced by recombinant HCV core protein was a specific effect, because the HCV envelope protein E2 interacting with CD81 as well as LPS did not induce increased expression of fibrogenic genes. Furthermore, activation of HSC by HCV core protein showed a dose-dependent kinetics. In addition, LX-2 cells could be stimulated by a truncated core protein narrowing the critical sequence for TLR2 interactions to amino acids 1 and 115 of the HCV core protein 
a
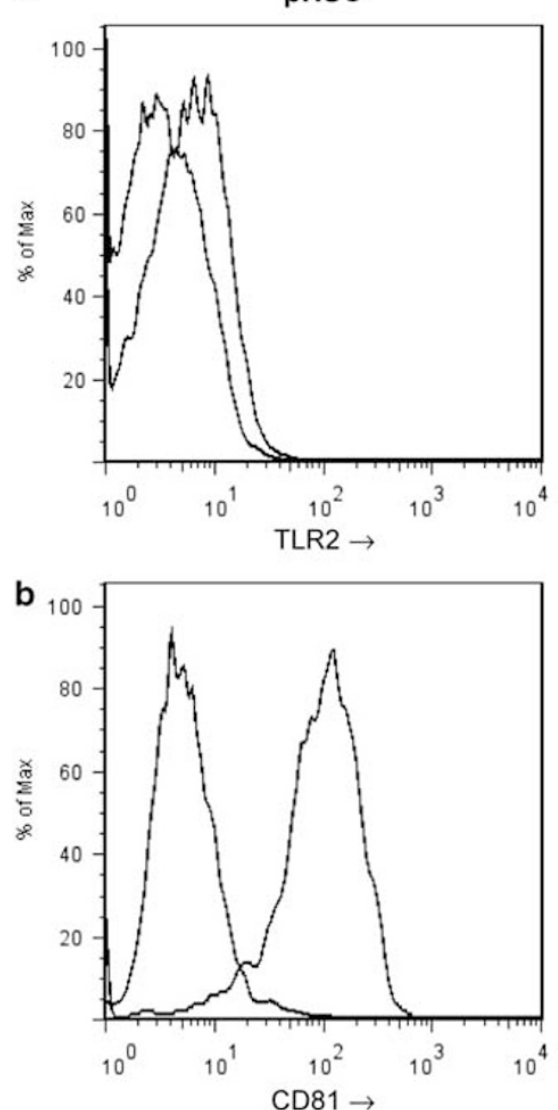

LX-2
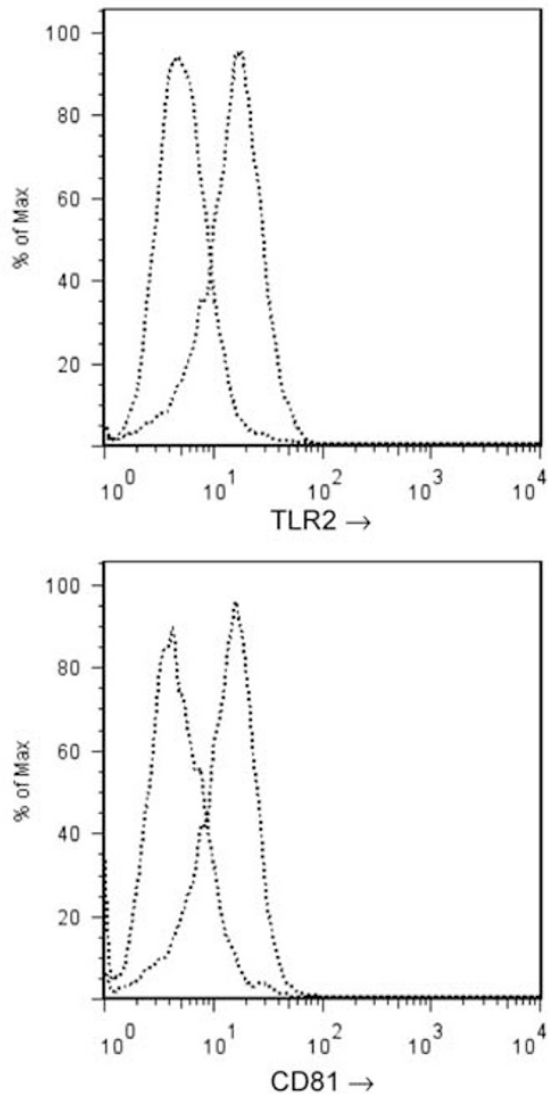

Figure 5 Human pHSC and LX-2 cells express toll-like receptor 2 (TLR2) and CD81. Flow cytometric analysis shows expression of TLR2 (a) and CD81 (b) by pHSC (black line) and LX-2 cells (dotted line) compared with the isotype-matched control antibodies.

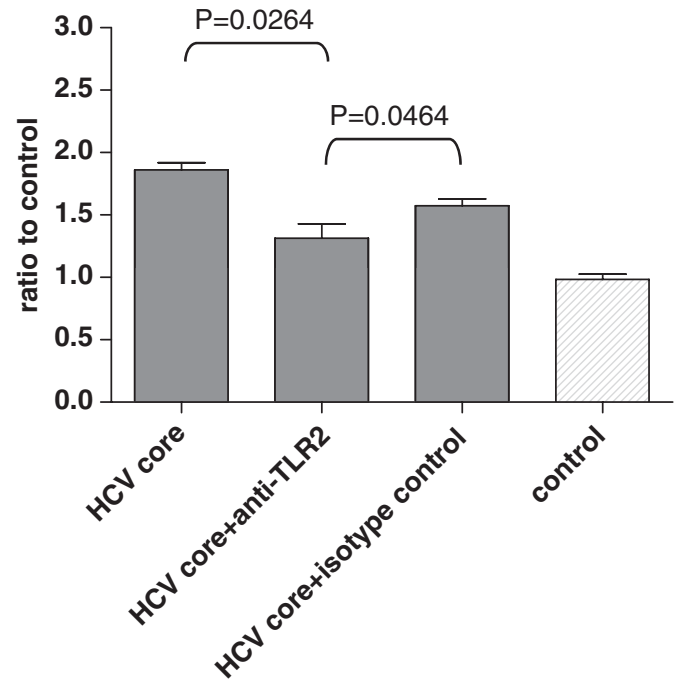

Figure 6 Induction of COL1A1-mRNA expression is inhibited by blockade of the TLR2 receptor. Serum-starved LX-2 cells were stimulated with HCV core protein alone and after preincubation with the neutralizing TLR2antibody (TL2.1), respectively. The figure shows the mRNA-expression levels from three independent experiments. Increase in gene expression of COL1A1 is shown in comparison with untreated controls. in line with previous data. ${ }^{30}$ The dimension of the effects seen in our experiments correspond well with previous works analyzing the induction of COL1A1, ${ }^{28,36} M M P 2$ and TIMP1. ${ }^{37}$

The fibrogenic effects could be demonstrated for both, human primary HSCs and the permanent human HSC line LX-2. Cultured primary cells represent an authentic target to characterize physiological and pathological reactions in liver fibrosis. However, they lack unlimited access, and exhibit considerable amount of heterogeneity and a limited life span. ${ }^{38}$ As characterized by Xu et al ${ }^{33}$ immortalized LX-2 cells retain key features of human HSCs in tissue culture making them a suitable model for cell culture-based studies of human hepatic fibrosis providing a consistent state of activation in order to obtain reproducible and reliable results. ${ }^{39}$ However, LX-2 cells constitute a constantly proliferating cell that does not fully reflect HSC in the quiescent state. For this reason we also studied primary human HSCs. Of note, primary HSC and LX-2 cells both express CD81 and TLR2 (Figure 5), surface molecules that can bind HCV proteins and exhibited similar gene activation patterns on exposure to $\mathrm{HCV}$ core protein. This finding strengthens the concept that HCV core protein acts directly on human HSC. 
a
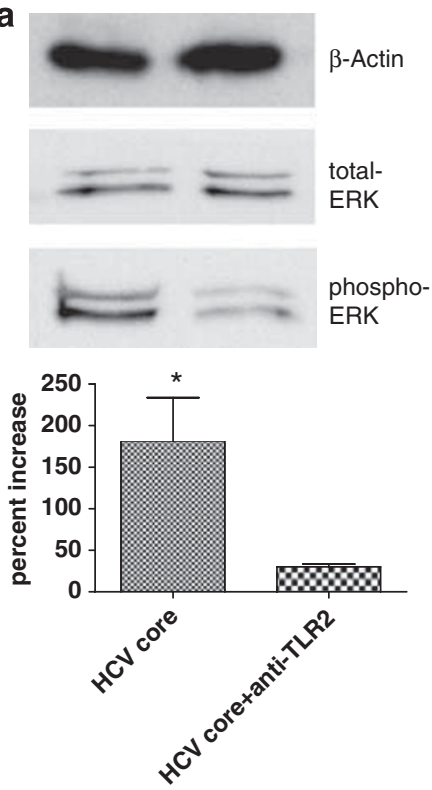

b
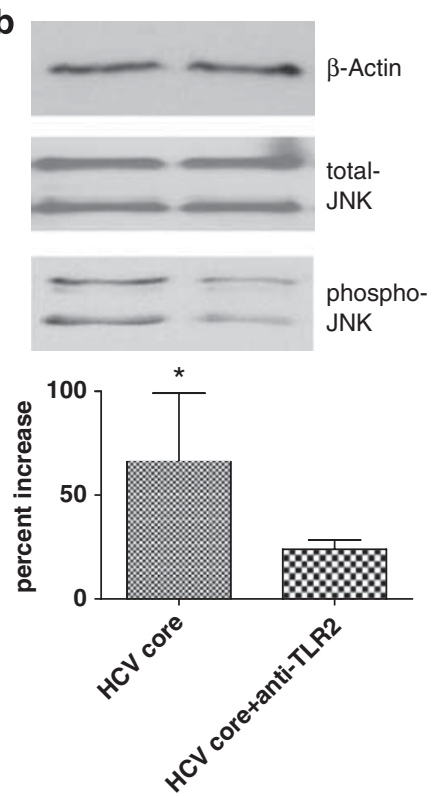

c
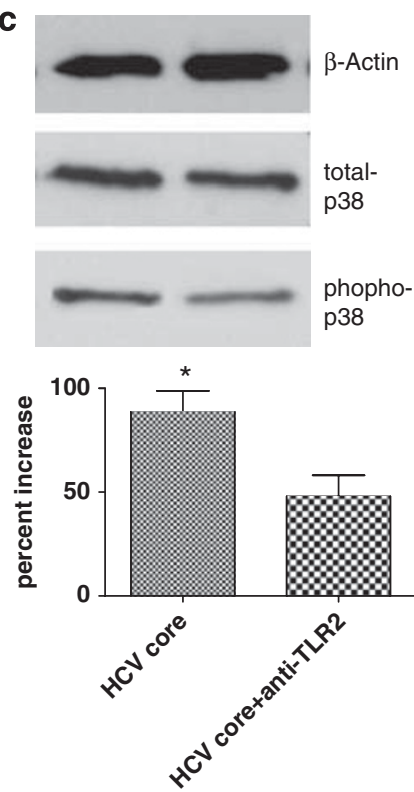

Figure 7 HCV core protein activates TLR2-dependent signaling pathways involving ERK1/2 (a), JNK (b) and p38 MAPK (c). Serum-starved LX-2 cells were

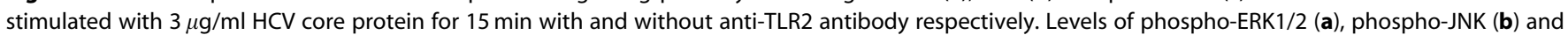
phopho-p38 MAPK (c) were determined by western blot analysis using $20 \mu \mathrm{g}$ of total cellular protein. A representative blot and a densitometric analysis of three independent experiments are shown. Increase in protein levels are shown by percentage in comparison with untreated controls. ${ }^{\star} P<0.05$.

Previous own findings and a report published by Dolganiuc et $a^{29}$ also suggested activation of TLR2 by HCV core protein. ${ }^{30}$ Human primary HSCs LX-2 both express TLR2. Of note, unlike the isotype control incubating HSC with a neutralizing TLR2 antibody prior to HCV core, protein exposure blocked mRNA upregulation of profibrogenic genes in LX-2 cells confirming that gene activation was triggered by the interaction of HCV core protein with TLR2.

Bataller et $a l^{28}$ previously reported that $\mathrm{HCV}$ core protein transduced into HSC by adenoviral vectors induce profibrogenic effects in this cell type, and in particular increased expression of procollagen type I. Independently from the possibility that HCV might enter into HSC to exert the above effects, our data suggest that its core protein may cause fibrogenic effects also by interacting with TLR2 on the plasma membrane. Bataller et al also demonstrated activation of intracellular signal transduction pathways, but in contrast to our results failed to demonstrate upregulation of collagen mRNA in rat HSC in response to HCV core protein. Apart from species-specific differences discrepancies to our findings could also be the result of the lower concentration of $10 \mathrm{ng} / \mathrm{ml}$ of HCV core protein which they used in their experiments.

HCV core protein is detectable in the serum of chronically HCV-infected patients at concentrations of 100-200 pg/ $\mathrm{ml},{ }^{40,41}$ and much higher concentrations may be assumed in states of high viral replication such as for instance occurs in fibrosing cholestatic hepatitis. ${ }^{42}$ Thus, under such conditions HSC are likely to become exposed to locally high concentrations of HCV proteins which can directly trigger fibrogenesis in HSC via TLR2-pathways independently from any tissue damage.

It has been reported that activation of TLR2 increases activity of ERK1/2, p38 and JNK MAPK. Accordingly our western blot analysis indicated that HCV core protein leads to increased phosphorylation of ERK1/2, p38 and JNK in LX-2 cells. Blocking TLR2 with a TLR2-specific antibody in turn reversed the increased phosphorylation confirming that $\mathrm{HCV}$ core protein exerts its effects on fibrogenic genes via TLR2 activation.

In line with our results, Bataller et al found increased phosphorylation of ERK1/2 in HSC. However, in contrast to our experiments, these authors did not find HCV-induced phophorylation of JNK and p38 MAPK. As stated above, such differences might reflect differences in the experimental settings, eg, differences in species. Considering the many different functions and effects of the MAPK pathways, it must be assumed that HCV core protein can exert diverse effects in the liver. Thus, the role of HCV proteins in chronic HCV infection needs further investigation. On the other hand, fibrogenic effects induced by the activation of MAPK pathways have been shown for a variety of different other stimuli that converge at the level of transcription of fibrogenic genes. ${ }^{36,43}$ Thus, direct activation of fibrogenesis by HCV core protein may have considerable pathophysiological relevance.

In summary, we provide evidence that $\mathrm{HCV}$ core protein induces HSC activation in a TLR2-dependent manner. These results suggest that HCV core protein can directly contribute to the hepatic fibrogenesis in HCV-infected 
patients. The results introduce a new aspect of HCV biology potentially relevant for the understanding of the pathogenesis of HCV-induced liver fibrosis and a basis for possible new antifibrotic therapy strategies.

\section{ACKNOWLEDGEMENT}

This study was funded by BONFOR (O-107.0097) to MC, the Deutsche Krebshilfe (107865) to HDN and US, and the SFB TR57 TP12 of the Deutsche Forschungsgemeinschaft to JN and US.

\section{DISCLOSURE/CONFLICT OF INTEREST}

The authors declare no conflict of interest.

1. Poynard T, Bedossa P, Opolon P. Natural history of liver fibrosis progression in patients with chronic hepatitis C. The OBSVIRC, METAVIR, CLINIVIR, and DOSVIRC groups. Lancet 1997;349:825-832.

2. Schuppan D, Krebs $A$, Bauer $M$, et al. Hepatitis $C$ and liver fibrosis. Cell Death Differ 2003;10(Suppl 1):S59-S67.

3. Friedman SL. Cellular sources of collagen and regulation of collagen production in liver. Semin Liver Dis 1990;10:20-29.

4. Sato M, Suzuki S, Senoo H. Hepatic stellate cells: unique characteristics in cell biology and phenotype. Cell Struct Funct 2003;28:105-112.

5. Hautekeete ML, Geerts A. The hepatic stellate (Ito) cell: its role in human liver disease. Virchows Arch 1997;430:195-207.

6. Ramadori G, Saile B. Inflammation, damage repair, immune cells, and liver fibrosis: specific or nonspecific, this is the question. Gastroenterology 2004;127:997-1000.

7. Geerts A, Vrijsen R, Rauterberg J, et al. In vitro differentiation of fat-storing cells parallels marked increase of collagen synthesis and secretion. J Hepatol 1989;9:59-68.

8. Wong L, Yamasaki G, Johnson RJ, et al. Induction of beta-plateletderived growth factor receptor in rat hepatic lipocytes during cellular activation in vivo and in culture. J Clin Invest 1994:94:1563-1569.

9. Schmitt-Graff A, Kruger S, Bochard F, et al. Modulation of alpha smooth muscle actin and desmin expression in perisinusoidal cells of normal and diseased human livers. Am J Pathol 1991;138:1233-1242.

10. Ramadori G, Veit T, Schwogler S, et al. Expression of the gene of the alpha-smooth muscle-actin isoform in rat liver and in rat fat-storing (ITO) cells. Virchows Archiv 1990;59:349-357.

11. Weiskirchen $\mathrm{R}$, Moser $\mathrm{M}$, Weiskirchen $\mathrm{S}$, et al. LIM-domain protein cysteine- and glycine-rich protein 2 (CRP2) is a novel marker of hepatic stellate cells and binding partner of the protein inhibitor of activated STAT1. Biochem J 2001;359(Part 3):485-496.

12. Cassiman D, Libbrecht L, Desmet V, et al. Hepatic stellate cell/ myofibroblast subpopulations in fibrotic human and rat livers. J Hepatol 2002;36:200-209.

13. Iredale JP. Tissue inhibitors of metalloproteinases in liver fibrosis. Int J Biochem Cell Biol 1997;29:43-54.

14. Arthur MJ, Friedman SL, Roll FJ, et al. Lipocytes from normal rat liver release a neutral metalloproteinase that degrades basement membrane (type IV) collagen. J Clin Invest 1989;84:1076-1085.

15. Murphy G. Matrix metalloproteinases and their inhibitors. Acta Orthop Scand Suppl 1995;266:55-60.

16. Murphy $G$, Stanton $H$, Cowell $S$, et al. Mechanisms for pro matrix metalloproteinase activation. APMIS 1999;107:38-44.

17. Suzuki T, Aizaki $H$, Murakami $K$, et al. Molecular biology of hepatitis C virus. J Gastroenterol 2007:42:411-423.

18. Tellinghuisen $T L$, Rice $C M$. Interaction between hepatitis $C$ virus proteins and host cell factors. Curr Opin Microbiol 2002;5:419-427.

19. Dubuisson J. Hepatitis C virus proteins. World J Gastroenterol 2007;13:2406-2415

20. McLauchlan J. Properties of the hepatitis C virus core protein: a structural protein that modulates cellular processes. J Viral Hepat 2000;7:2-14.

21. Saito $K$, Meyer $K$, Warner $R$, et al. Hepatitis $C$ virus core protein inhibits tumor necrosis factor alpha-mediated apoptosis by a protective effect involving cellular FLICE inhibitory protein. J Virol 2006;80:4372-4379.
22. Hosui A, Takehara T, Ohkawa K, et al. Suppressive effect on hepatocyte differentiation of hepatitis $C$ virus core protein. Biochem Biophys Res Commun 2006:346:1125-1130.

23. Large MK, Kittlesen DJ, Hahn YS. Suppression of host immune response by the core protein of hepatitis $\mathrm{C}$ virus: possible implications for hepatitis C virus persistence. J Immunol 1999;162:931-938.

24. Eisen-Vandervelde AL, Waggoner $\mathrm{SN}, \mathrm{Yao} Z \mathrm{ZQ}$, et al. Hepatitis $\mathrm{C}$ virus core selectively suppresses interleukin-12 synthesis in human macrophages by interfering with AP-1 activation. J Biol Chem 2004;279:43479-43486.

25. Lai MM. Hepatitis $C$ virus proteins: direct link to hepatic oxidative stress, steatosis, carcinogenesis and more. Gastroenterology 2002;122:568-571.

26. Dolganiuc $A$, Kodys $K$, Kopasz $A$, et al. Hepatitis $C$ virus core and nonstructural protein 3 proteins induce pro- and anti-inflammatory cytokines and inhibit dendritic cell differentiation. J Immunol 2003;170:5615-5624.

27. Nattermann J, Nischalke HD, Hofmeister V, et al. The HLA-A2 restricted T cell epitope HCV core 35-44 stabilizes HLA-E expression and inhibits cytolysis mediated by natural killer cells. Am J Pathol 2005;166: 443-453.

28. Bataller $\mathrm{R}$, Paik $\mathrm{YH}$, Lindquist $\mathrm{JN}$, et al. Hepatitis $\mathrm{C}$ virus core and nonstructural proteins induce fibrogenic effects in hepatic stellate cells. Gastroenterology 2004;126:529-540.

29. Dolganiuc A, Oak S, Kodys K, et al. Hepatitis C core and nonstructural 3 proteins trigger toll-like receptor 2-mediated pathways and inflammatory activation. Gastroenterology 2004;127:1513-1524.

30. Feldmann G, Nischalke HD, Nattermann J, et al. Induction of interleukin-6 by hepatitis $C$ virus core protein in hepatitis C-associated mixed cryoglobulinemia and B-cell non-Hodgkin's lymphoma. Clin Cancer Res 2006;12:4491-4498.

31. Duesberg $U$, von dem Bussche A, Kirschning C, et al. Cell activation by synthetic lipopeptides of the hepatitis $C$ virus $(\mathrm{HCV})$-core protein is mediated by toll like receptors (TLRs) 2 and 4 . Immunol Lett 2002;84:89-95

32. O'Neill LA, Bowie AG. The family of five: TIR-domain-containing adaptors in Toll-like receptor signalling. Nat Rev Immunol 2007;7:353-364.

33. Xu L, Hui AY, Albanis E, et al. Human hepatic stellate cell lines, LX-1 and LX-2: new tools for analysis of hepatic fibrosis. Gut 2005;54:142-151.

34. Friedman SL. Seminars in medicine of the Beth Israel Hospital, Boston. The cellular basis of hepatic fibrosis. Mechanisms and treatment strategies. N Engl J Med 1993;328:1828-1835.

35. Friedman SL. Mechanisms of hepatic fibrogenesis. Gastroenterology 2008; 134:1655-1669.

36. Che J, Chan ES, Cronstein BN. Adenosine A2A receptor occupancy stimulates collagen expression by hepatic stellate cells via pathways involving protein kinase $\mathrm{A}$, Src, and extracellular signal-regulated kinases $1 / 2$ signaling cascade or p38 mitogen-activated protein kinase signaling pathway. Mol Pharmacol 2007;72:1626-1636.

37. Shi YF, Fong CC, Zhang Q, et al. Hypoxia induces the activation of human hepatic stellate cells LX-2 through TGF-beta signaling pathway. FEBS Lett 2007;581:203-210.

38. Herrmann J, Gressner AM, Weiskirchen R. Immortal hepatic stellate cell lines: useful tools to study hepatic stellate cell biology and function? J Cell Mol Med 2007;11:704-722.

39. Gieseler RK, Marquitan G, Schlattjan M, et al. Hepatocyte apoptotic bodies encasing nonstructural HCV proteins amplify hepatic stellate cell activation: implications for chronic hepatitis C. J Viral Hepat; published online 15 August 2010 [e-pub ahead of print].

40. Tanaka $E$, Ohue $C$, Aoyagi $K$, et al. Evaluation of a new enzyme immunoassay for hepatitis $C$ virus $(\mathrm{HCV})$ core antigen with clinical sensitivity approximating that of genomic amplification of HCV RNA. Hepatology 2000;32:388-393.

41. Tanaka E, Kiyosawa K, Matsumoto A, et al. Serum levels of hepatitis $C$ virus core protein in patients with chronic hepatitis $C$ treated with interferon alfa. Hepatology 1996;23:1330-1333.

42. Fenwick F, Bassendine MF, Agarwal K, et al. Immunohistochemical assessment of hepatitis $C$ virus antigen in cholestatic hepatitis after liver transplantation. J Clin Pathol 2006;59:174-178.

43. Chen A, Davis BH. UV irradiation activates JNK and increases alphal(I) collagen gene expression in rat hepatic stellate cells. J Biol Chem 1999;274:158-164. 